\title{
Erratum to: Unglazed pottery from the masjed-i jom'e of Isfahan (Iran): technology and provenance
}

\author{
Alberto De Bonis ${ }^{1}$ - Maria D'Angelo ${ }^{2}$ • Vincenza Guarino ${ }^{1}$ - Serena Massa ${ }^{3}$. \\ Faribah Saiedi Anaraki ${ }^{4}$ Bruno Genito ${ }^{5}$. Vincenzo Morra ${ }^{1}$
}

Published online: 17 November 2016

(C) Springer-Verlag Berlin Heidelberg 2016

\section{Erratum to: Archaeol Anthropol Sci \\ DOI 10.1007/s12520-016-0407-z}

The corresponding author would like modify the last part of the Acknowledgments section, where he inserted two more people that they wish to thank. The modified text is included at this article.

Aknowledgments This research was supported by the following grants: V.M. (LR 5/02 2008, 04-C00001720) and funds from the Dipartimento di Scienze della Terra, dell'Ambiente e delle Risorse (DiSTAR) of the Università degli Studi di Napoli Federico II (V.M.). Thanks are due to the following organisations of the Islamic Republic of Iran: Research Center of the Iranian Cultural Heritage, Handicrafts and Tourism Organization (RCICHHTO) of Tehran, Iranian Centre for Archaeological Research (ICAR) of Tehran and Isfahan and Embassy of Italy at Tehran. Thanks are also due to institutions of the Italian Republic: Ministry of Foreign Affairs, Embassy of Islamic Republic of Iran in Rome, Istituto Italiano per l'Africa e l'Oriente (IsIAO), Centro Interdipartimentale di Servizi per l'Archeologia (CISA) and Università degli Studi di Napoli "L'Orientale".

The authors express their gratitude to the two anonymous referees for constructive comments and useful suggestions that significantly improved this manuscript. The authors also thank Leone Melluso for its helpful suggestions and Beatrice Bizzaro for the English revision of the manuscript. Finally, the authors thank Nader Akbar Mahdi, a craftsman of the ceramic workshop in Isfahan, for his help in finding clay and technical support.
The online version of the original article can be found at http://dx.doi. org/10.1007/s12520-016-0407-z.

\section{Alberto De Bonis}

alberto.debonis@unina.it

1 Dipartimento di Scienze della Terra, dell'Ambiente e delle Risorse (DiSTAR), Università degli Studi di Napoli Federico II, Via Mezzocannone 8, 80134 Naples, Italy

2 Independent Researcher, Via Pietro Imbriaco 25, 84051 Centola, SA, Italy

3 Università Cattolica del Sacro Cuore, Milan, Italy

4 Iranian Centre for Archaeological Research, Isfahan, Iran

5 Dipartimento Asia Africa e Mediterraneo, Università degli Studi di Napoli “L'Orientale”, Piazza S. Domenico Maggiore 12,

Naples 80134, Italy 